\title{
ARTIGO REVISÃ0: Aspectos da Reologia e da Estabilidade de Suspensões Cerâmicas. \\ Parte III: Mecanismo de Estabilização Eletroestérica de Suspensões com Alumina.
}

\section{(REVIEW ARTICLE: Aspects of Rheology and Stability of Ceramic Suspensions. Part III: Electrosteric Stabilization Mechanism of Alumina Suspensions).}

\author{
F. S. Ortega, V. C. Pandolfelli, J. A. Rodrigues, D. P. F. de Souza \\ Universidade Federal de São Carlos, DEMa. \\ Via Washington Luis, Km 235, C.P. 676. \\ 13565-905, São Carlos - SP. \\ Tel.: (016) 274-8250, Fax: (016) 272-7404 \\ e-mail:vicpando@power.ufscar.br
}

\section{Resumo}

Esta terceira e última parte da revisão sobre os aspectos reológicos e de estabilização de suspensões com pós cerâmicos vem reunir a aplicação dos conhecimentos adquiridos nas primeiras duas partes publicadas anteriormente.

Aqui, os fenômenos eletrostático devido à dupla camada elétrica, e estérico, relacionado à adsorção de moléculas poliméricas, são combinados para explicar o mecanismo eletroestérico de estabilização de suspensões cerâmicas. Os defloculantes que atuam através desse mecanismo abrangem uma classe específica de polímero denominada polieletrólitos, a qual é constituída por macromoléculas ionizáveis quando em solução.

O estudo da forma com que os polieletrólitos atuam justifica-se devido à larga utilização desta classe de polímeros na indústria cerâmica. Os ácidos poliacrílico (PAA) e polimetacrílico (PMAA) são exemplos de polieletrólitos amplamente utilizados no processo de materiais à base de alumina.

Dá-se destaque à influência do $\mathrm{pH}$ do meio e da presença de íons, sendo novamente aqui importante o conceito de força iônica da suspensão.

Como aplicação prática, apresenta-se a estabilidade do sistema alumina-PMAA, reportando-se sobre o comportamento da viscosidade e da efetiva defloculação da suspensão.

Este estudo é concluído apresentando resultados do efeito do peso molecular sobre a viscosidade, chamando atenção para o fato de que não basta definir apenas a classe de polímero a ser usada, sendo também fundamental especificar o peso molecular médio do polímero selecionado.

\section{4 - Estabilização Eletroestérica: Aplicação para a Alumina}

\section{1 - Introdução}

O uso de polieletrólitos para promover a estabilização de suspensões contra a floculação tem sido uma das alternativas mais

\section{Abstract}

The third and last part of this review about stabilization and rheological aspects of ceramic suspension gathers the knowledge in the two parts previously published.

Here, the electrostatic and steric phenomena, related to the electrical double layer and polymeric molecules adsorption, respectively, are combined to explain the electrosteric stabilization mechanism of ceramic suspensions. The deflocculants used to afford such dispersion mechanism cover a specific kind of polymer, named polyelectrolytes, which are macromolecules that are ionizable in solution.

The study of how the polyelectrolytes behave is justified due to the large use of this polymeric product in the ceramic industry. Polyacrylic acid (PAA) and polymethacrylic acid (PMAA) are examples of polyelectrolytes that are widely used in the processing of alumina based materials.

The medium $\mathrm{pH}$ and ion concentration are strengthened, and the importance of the ionic strength is emphasized.

As a practical application, the stability of aluminaPMAA system is presented. The viscosity and dispersion behaviour of the suspension are also reported.

This study is concluded presenting results concerning the effect of molecular weigth on the suspension viscosity, and shows that it is not enough to select a polymer considering just its class. It is fundamental to specify the average molecular weight of the selected polymer. utilizadas na indústria cerâmica. Esta classe de polímero caracteriza-se por apresentar grupos ionizáveis às cadeias, proporcionando um efeito de repulsão eletrostática que se soma à barreira estérica oferecida por moléculas poliméricas. ${ }^{(1)}$

Entre os polieletrólitos mais utilizados na indústria cerâmica, o ácido poliacrílico (PAA), e o ácido polimetacrílico (PMAA) 
estão entre os mais comuns, e sua eficácia fez com que seu uso se proliferasse, principalmente no processamento de materiais à base de alumina. Por esse motivo, esta seção irá se referir basicamente a esses dois polieletrólitos, embora o raciocínio desenvolvido possa se estender a outras classes de polímeros. De um modo geral, nos produtos vendidos comercialmente os grupos ácidos desses polieletrólitos são neutralizados com hidróxido de sódio, ou amônia, formando respectivamente o poliacrilato e o polimetacrilato de sódio ou amônia. A figura 1 mostra um esquema das cadeias desses dois polímeros.

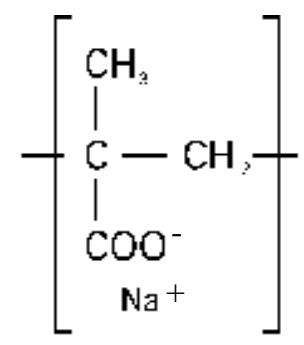

PMAA

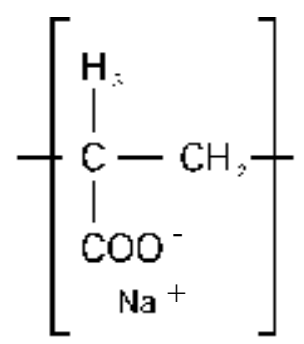

PAA
Figura 1 - Unidades repetitivas do polimetacrilato (PMAA) e do poliacrilato (PAA) de sódio. ${ }^{(2)}$

\section{2 - Dissociação de Polieletrólitos e Conformação Molecular}

Os grupos $\mathrm{COOH}$, quando em solução aquosa sofrem dissociação, segundo a reação ${ }^{(3)}$ :

$$
\mathrm{RCOOH} \leftrightarrow \mathrm{RCOO}^{-}+\mathrm{H}^{+}
$$

sendo que $\alpha$, a fração dissociada do grupo carboxil [RCOO-], é dada por:

$$
\alpha=\frac{\left[\mathrm{RCOO}^{-}\right]}{\left[\mathrm{RCOOH}^{-}\left[\mathrm{RCOO}^{-}\right]\right.}
$$

Os principais fatores a determinar o grau de dissociação das moléculas poliméricas são o pH e a concentração de íons na solução, ou força iônica. A figura 2 mostra a variação da fração dissociada em função do $\mathrm{pH}$ e da concentração de eletrólitos.

Em pHs acima de 8,5 (soluções básicas), o grau de dissociação dos sítios RCOOH é alto, de modo que $\alpha$ atinge valores ao redor de

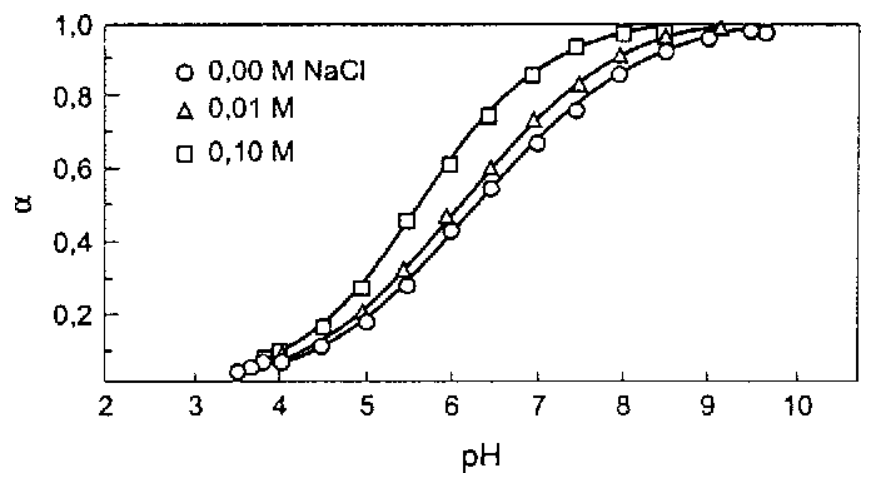

Figura 2 - Variação do grau de dissociação do PMAA em função do pH, para meios com diferentes forças iônicas. ${ }^{(4)}$
1. À medida que o pH se torna mais ácido, o grau de dissociação também diminui, até que ao atingir valores abaixo de 3,4 o coeficiente $\alpha$ se torna igual a zero. Neste ponto, não ocorre dissociação alguma, e a molécula torna-se neutra e insolúvel em água.

Já a presença de sais em solução tem a propriedade de deslocar o equilíbrio da reação $(\mathrm{T})$, aumentando a fração dissociada para um $\mathrm{pH}$ fixo. Isso ocorre porque uma vez dissociados, os sítios COOsão estabilizados por íons positivos, tornando a recombinação com os íons hidroxônio $\left(\mathrm{H}_{3} \mathrm{O}^{+}\right)$mais difícil. Deste modo, quanto maior a força iônica do meio, maior será o grau de dissociação do polímero. ${ }^{(4)}$

A conformação que as cadeias poliméricas adquirem na solução depende diretamente do grau de dissociação do polieletrólito. Quando a dissociação ocorre em grau elevado, as cargas negativas adquiridas por cada sítio se repelem, e a cadeia assume uma conformação estendida. Por outro lado, se o grau de dissociação é baixo, ou nulo, as cadeias adquirem uma conformação enovelada, aproximando-se à insolubilidade.

\section{3 - Densidade de Cargas Superficiais e pH}

A superfície de partículas sólidas caracteriza-se pela existência de cargas positivas e negativas. Dependendo do $\mathrm{pH}$, a densidade superficial de uma ou de outra será maior, resultando em uma carga superficial líquida ${ }^{(5)}$, como mostra a figura 3.

Nos óxidos, a densidade de cargas superficiais depende essencialmente do $\mathrm{pH}$ da solução, e é determinada por um balanço entre os sítios positivos, negativos e neutros existentes na superfície. Assim, em pHs ácidos, há predomínio de sítios positivos, enquanto que em $\mathrm{pHs}$ básicos, predominam os sítios negativos. $\mathrm{O} \mathrm{pH}$ no qual o número de sítios positivos é igual ao número de sítios negativos é denominado ponto de carga zero (PCZ), e resulta em uma superfície neutra.

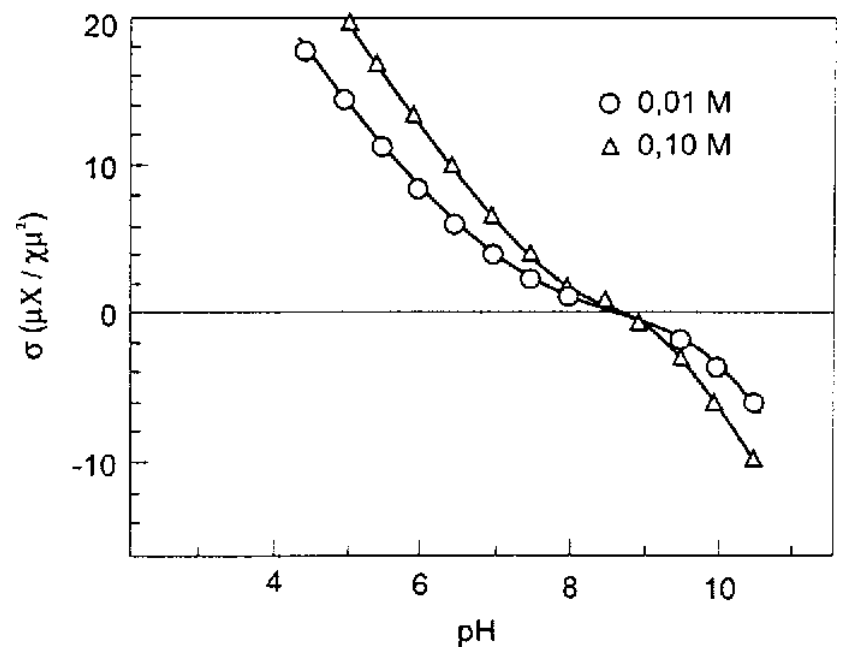

Figura 3 - Variação da densidade de cargas superficiais com pH, em suspensões de $\mathrm{Al}_{2} \mathrm{O}_{3}$ com diferentes forças iônicas. ${ }^{(4)}$

\section{4 - Adsorção de PMAA Sobre a Superfície de Alumina}

A quantidade de polieletrólitos adsorvida, a conformação adquirida, e a energia com que as moléculas se liguam à superfície das partículas são dependentes das interações eletrostáticas entre a 
superfície e as moléculas. Como foi visto nos itens anteriores, as características eletrostáticas da superfície das partículas e das cadeias poliméricas dependem essencialmente do $\mathrm{pH}$ e da força iônica da suspensão. Assim, conclui-se que essas propriedades determinarão o tipo de interação entre as cadeias e a superfície das partículas. A Figura 4 mostra a quantidade de PMAA (um polieletrólito aniônico) adsorvido sobre a superfície de alumina, em função do $\mathrm{pH}$.

Como foi discutido anteriormente, quando o $\mathrm{pH}$ é menor do que aquele correspondente ao ponto de carga zero, a densidade de carga superficial das partículas é positiva. Deste modo, se o polieletrólito em suspensão for uma espécie aniônica, e estiver dissociado nesta faixa de $\mathrm{pH}$, ocorrerá o que se denomina adsorção de alta afinidade, ou seja, a adsorção de moléculas negativas sobre uma superfície positiva. Neste caso, a alta afinidade entre as moléculas e as partículas fará com que todas as moléculas adicionadas à solução sejam prontamente adsorvidas, até que a superfície seja totalmente recoberta. Quando isto for atingido, todo o polímero adicionado em excesso permanecerá em solução (região de platô), já que não existirão mais sítios disponíveis para que a adsorção continue. Este comportamento é abservado na figura 4, para os $\mathrm{pHs}$ abaixo de 8,8 , que é o ponto de carga zero da alumina utilizada no experimento. Nota-se que a região de platô é atingida prontamente, sem variações gradativas na inclinação da curva.

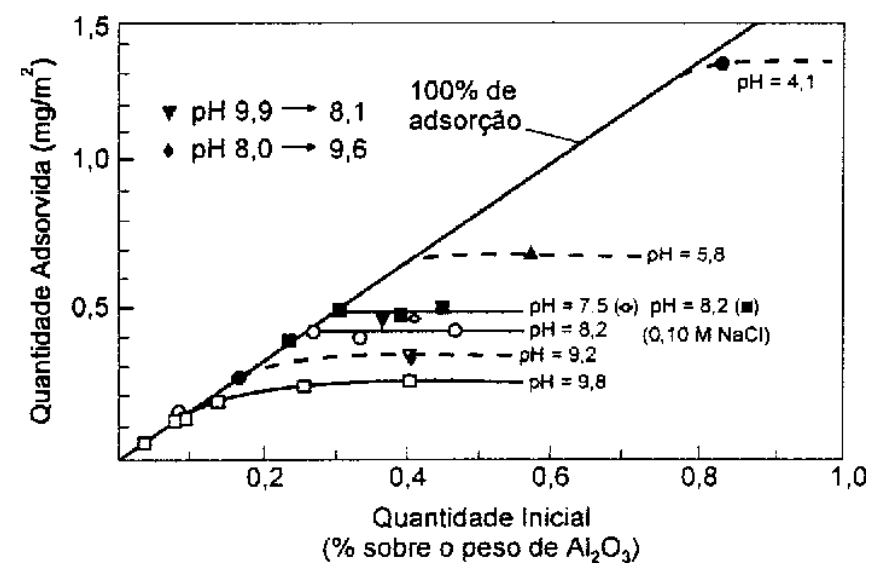

Figura 4 - Quantidade de PMAA adsorvido na superficie de $\mathrm{Al}_{2} \mathrm{O}_{3}$ em função da quantidade inicial na suspensão. ${ }^{(4)}$

Para pHs acima de 8,8 a superfície das partículas estará com uma densidade de carga superficial negativa, de modo que a similaridade de cargas entre o PMAA e a superfície resultará em uma barreira à adsorção. Como resultado, será observada uma transição gradativa para a região de platô. Nesta região de transição, nem todo polímero adicionado será adsorvido, mas parte dele ficará em solução, de modo que para aumentar a área recoberta por partículas será necessário aumentar a concentração de polímero em solução. Deve-se ressaltar que embora as cadeias poliméricas e a carga líquida na superfície das partículas possuam mesmo sinal, a adsorção continua ocorrendo, pois continuam a existir sítios superficiais positivos, ainda que em menor quantidade que os negativos.

A figura 4 mostra também que polieletrólitos são relativamente insensíveis à adição de sal à solução. Nota-se que a suspensão em pH 8,2 permaneceu estável mesmo após a adição de 0,1 M de $\mathrm{NaCl}$. O efeito de blindagem dos íons $\mathrm{Na}^{+}$sobre os sítios negativos aumenta o caráter neutro das moléculas, o que favorece a conformação na forma de loops e caudas. Como a área recoberta por moléculas com essa conformação é menor, é necessário maior quantidade de polieletrólito para recobrir totalmente a superfície das partículas. Deste modo, o efeito estérico, cuja contribuição é pequena no caso de cadeias com cargas elevadas, passa a ser decisivo para a estabilidade das suspensões com alta concentração de íons.

Pode-se observar ainda na figura 4 que as cadeias são ligadas às partículas com energia relativamente elevada. Uma suspensão preparada inicialmente com $\mathrm{pH}$ de 9,9 (na qual o excesso de polímero estava em solução) foi posteriormente ajustada para um pH de 8,1 (região em que ocorre adsorção de alta afinidade). Nesta transição, o excesso de polímero em solução foi adsorvido até o nível esperado para uma solução com pH 8,1. Por outro lado, uma suspensão preparada inicialmente com $\mathrm{pH}$ 8,0 foi posteriormente ajustada para pH 9,6. Embora tenha ocorrido dessorção parcial do polímero a quantidade que permaneceu adsorvida ficou em um patamar equivalente ao do pH 9,2, ou seja, a adsorção não é completamente reversível.

\section{5 - Adsorção e Estabilidade}

Tem-se a idéia generalizada de que a adição de defloculante sempre aumenta a estabilidade de uma suspensão. Esta não é , entretanto, uma regra geral, como mostra a figura 5.

Nesta figura, a altura de sedimentação e o potencial zeta de uma suspensão de alumina em água são avaliados em função da quantidade de defloculante adicionada. Como se sabe ${ }^{(6)}$, a altura de sedimentação é uma medida indireta do grau de floculação de uma suspensão. Em suspensões defloculadas, as partículas estão individualizadas, e podem formar um sedimento com alto grau de empacotamento, e altura pequena. Já suspensões não defloculadas apresentam flocos, que são estruturas abertas, pouco densas, e bem
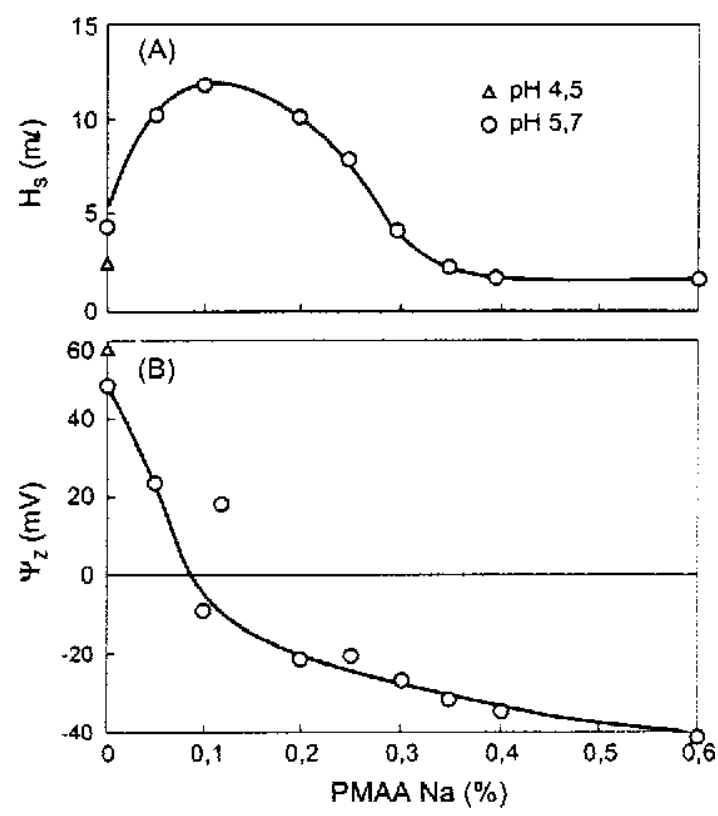

Figura 5 - Volume de sedimentação $\left(H_{s}\right)$ e potencial zeta $\left(\psi_{z}\right)$ em função da quantidade de defloculante adicionada a uma suspensão de $\mathrm{Al}_{2} \mathrm{O}_{3}{ }^{(4)}$. 
maiores. Deste modo, estas partículas não podem formar uma estrutura com alto grau de empacotamento, e resultam em todas de menor densidade, com altura de sedimentação maior.

Como se observa na figura, pequenas adições de PMAA proporcionaram um aumento no volume de sedimentação da suspensão, bem como decréscimo no potencial zeta, ou seja, induziram a floculação do sistema. Isto pode ser explicado devido ao elevado potencial de superfície que se desenvolve em um $\mathrm{pH}$ de 5,7 no qual foi realizado o experimento. Este potencial é positivo, e seu valor em módulo proporciona uma dupla camada elétrica que é capaz de promover a estabilização eletrostática da suspensão. Ao ser adicionado o polieletrólito, a carga negativa dessas moléculas promoveu a neutralização dos sítios positivos existentes na superfície das partículas, fazendo o potencial zeta decrescer, e permitindo, portanto, que a floculação ocorresse. Maiores adicões de polieletrólito reverteram o potencial de superfície, proporcionando novo aumento (em módulo) do potencial zeta. Como resultado, o sistema voltou a estar defloculado, e o volume de sedimentação diminuiu.

É importante observar que a adição de $0,4 \%$ de PMAA proporcionou um potencial zeta de $-33 \mathrm{mV}$, que em módulo é menor do que o potencial devido apenas à dupla camada elétrica (sem a adição de defloculante), que foi de $+48 \mathrm{mV}$. Apesar disso, o volume do sedimento com defloculante foi menor que o volume do sedimento sem defloculante. Ou seja, embora a adição de $0,4 \%$ de defloculante tenha proporcionado um potencial zeta menor, o grau de defloculação da suspensão foi maior. O mesmo volume de sedimentação, sem o uso de defloculante, só foi obtido com uma suspensão de $\mathrm{pH} 4,5$, na qual verificou-se um potencial zeta da ordem de $58 \mathrm{mV}$. Esta é uma evidência de que muito embora a atuação do PMAA seja de caráter eminentemente eletrostático, há também uma contribuição do efeito estérico proporcionado pela adsorção polimérica sobre a superfície das partículas.

\section{6 - A Estabilidade do Sistema $\mathrm{Al}_{2} \mathrm{O}_{3}-\mathrm{PMAA}$}

A figura 6 mostra um mapa de estabilidade do sistema $\mathrm{Al}_{2} \mathrm{O}_{3}$ - PMAA, baseado em dados experimentais. ${ }^{(2)}$

A região acima da curva é estável, enquanto que a região abaixo da curva apresenta tendência à floculação. Para pHs eleva-

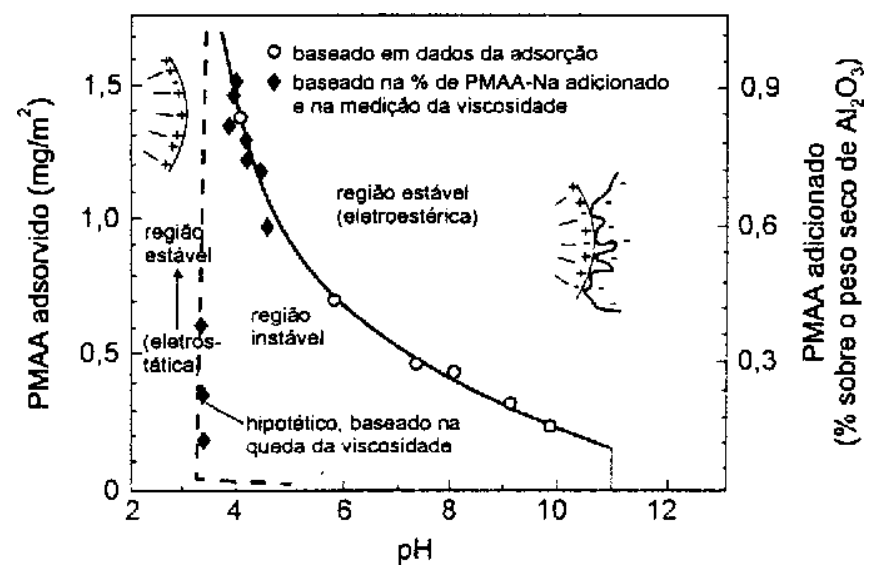

Figura 6 - Mapa de estabilidade contra floculação do sistema $\mathrm{Al}_{2} \mathrm{O}_{3}-\mathrm{PMAA}^{(2)}$ dos, a quantidade de polímero a ser adsorvida para atingir a estabilidade é menor do que em pHs ácidos, conforme já foi discutido anteriormente.

Nota-se que para pHs abaixo de 3,3 a suspensão se torna estável, independente da quantidade de polímero adicionada à suspensão. Nesta faixa de pH, o PMAA não se dissocia, e as moléculas tornam-se neutras. Assim a quantidade de polímero adsorvido passa a ser muito pequena, ou nula, já que a afinidade entre as cadeias poliméricas e a superfície das partículas se torna muito baixa. Nesta região, a estabilização é conseqüência unicamente da dupla camada elétrica que se desenvolve ao redor das partículas.

\section{7 - Reologia e Teor de Sólidos}

A viscosidade de suspensões varia de acordo com a fração volumétrica de sólidos, conforme foi discutido em seção anterior. Quanto maior a fração de sólidos, maior a viscosidade de uma suspensão ${ }^{(5,7)}$. A figura 7 mostra que o aumento na fração de sólidos provoca não só um aumento na viscosidade da suspensão, como também um estreitamento na faixa de $\mathrm{pH}$ em que a viscosidade é mínima.

Para frações de sólidos baixas, há uma larga faixa de $\mathrm{pH}$ em que a viscosidade da suspensão é mínima. À medida que a fração de sólidos se torna mais elevada, entretanto, a faixa de $\mathrm{pH}$ com viscosidade mínima se torna cada vez mais estreita. Observa-se ainda que o $\mathrm{pH}$ ótimo corresponde ao ponto de carga zero da alumina, que é em torno de 8,8 . Isso demonstra que em sistemas defloculados eletroestericamente haverá predomínio das cargas devidas ao polieletrólito, e não das cargas superficiais das partículas, já que em sistemas livres de defloculantes, neste $\mathrm{pH}$, há ausência de repulsão eletrostática entre as partículas, o que permite que as forças de van der Waals atuem livremente, provocando a floculação do sistema, e resultando em viscosidade máxima.

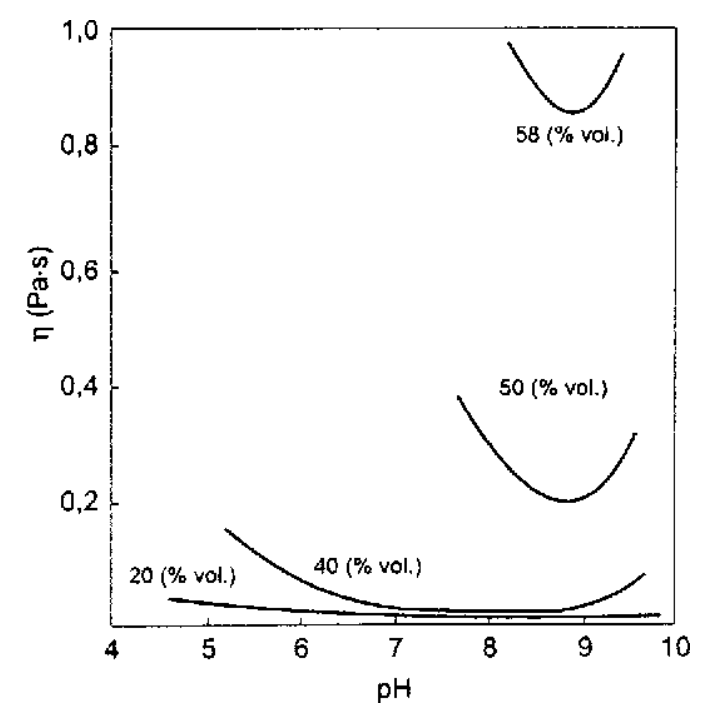

Figura 7 - Viscosidade ( $\eta$ ) em função do $p H$, para suspensões com diferentes frações volumétricas de sólidos. (2)

Há várias razões para que a viscosidade aumente à medida que se distancia do $\mathrm{pH}$ ótimo. Quando o $\mathrm{pH}$ aumenta em relação ao ponto de carga zero, passa a haver mais polímero não adsorvido, pois a densidade de carga superficial das partículas passa a ser ne- 
gativa, e não ocorre mais a adsorção de alta afinidade. Este fato, associado à baixa quantidade de água existente em suspensões com elevados teores de sólidos, torna a concentração de polímero em solução elevada, aumentando a viscosidade da fase líquida, e conseqüentemente da suspensão.

Já à medida que o $\mathrm{pH}$ diminui em relação ao ponto de carga zero, a quantidade de polímero recobrindo cada partícula se torna maior, ao mesmo tempo em que o grau de dissociação desses polímeros diminui. Ou seja, passa a haver menor quantidade de grupos funcionais em solução, diminuindo a barreira energética. Além disso, à medida que o pH se distancia do ponto de carga zero, aumenta a concentração de íons em solução, introduzidos com o ajuste do $\mathrm{pH}$, ou associados à maior quantidade de polieletrólito. Com isso, a força iônica aumenta consideravelmente, reduzindo a contribuição eletrostática proporcionada pelo polímero.

A tabela I reforça essas conclusões. Foi construída com base em alguns experimentos de Cesarano e Aksay ${ }^{(2,4)}$, relacionando o $\mathrm{pH}$ com certas propriedades de suspensões de alumina $(40 \% \mathrm{em}$ volume) estabilizadas com polimetacrilato de sódio.

Nesta tabela, a razão polimérica representa a fração da quantidade de polímero necessária para recobrir totalmente a superfície das partículas. Os fatores $\kappa_{\mathrm{a}}, \psi_{\zeta}$ e $\boldsymbol{c} \boldsymbol{V}$ representam a força iônica do meio, para o diâmetro a de partícula, o potencial zeta, e o cálculo da energia potencial de repulsão eletrostática entre as partículas a uma distância de10 nm, respectivamente. A coluna $\eta_{0}$ a $\eta_{10}$ mostra os valores da viscosidade inicial, e após 10 minutos sob uma taxa de cisalhamento de 9,3 $\mathrm{s}^{-1}$. A última coluna apresenta o resultado de uma observação qualitativa da estabilidade da suspensão, podendo ser floculada (F), estável (E), ou levemente floculada (LF).

A primeira conclusão a que se chega refere-se aos dados denominados A (segunda coluna da tabela). Ao se diminuir o $\mathrm{pH}$ de 8,8 para 4,6, mantendo-se sempre uma razão polimérica maior que 1 , ou seja, toda a superfície das partículas recoberta com polímero, observa-se aumento na força iônica do meio, de 152 para 325, ao mesmo tempo que há diminuição do módulo do potencial zeta de 32 para 13, e queda da energia potencial de repulsão, que inicialmente era de 0,6 J. Como conseqüência disso, há aumento na viscosidade da suspensão, bem como na variação da viscosidade com o tempo. Isso mostra que ocorre floculação do sistema com a queda do $\mathrm{pH}$, mesmo com as partículas estando totalmente recobertas com polímero. Confirma ainda a tese de que com queda do $\mathrm{pH}$ o polieletrólito passa a comportar-se cada vez mais como polímero neutro, ao passo que aumenta a concentração de íons em solução, associados à maior quantidade de polímero necessária para recobrir completamente a superfície das partículas, bem como ao ajuste do $\mathrm{pH}$, aumentando a força iônica do meio e diminuindo a repulsão eletrostática entre as partículas.Obtém-se, portanto, uma suspensão menos estável. Na verdade, para que a estabilização ocorra, observa-se que é necessário um potencial zeta máximo de $-20 \mathrm{mV}$ (para essa fração volumétrica de sólidos de 40\% em volume), mostrando que o polímero ainda representa algum grau de dissociação, e que ainda existem grupos funcionais carregados se estendendo na solução, proporcionando uma certa repulsão eletrostática.

A segunda conclusão que se tira refere-se aos dados denominados B. Através deles, mostra-se que a principal causa de ocorrência de floculação é o recobrimento incompleto das partículas com polímero. Observa-se que para razões poliméricas menores que 1 a floculação sempre ocorre, mesmo com potencial zeta de grande magnitude e alta energia de repulsão, como se verifica com o pH 9,5. Neste exemplo, nem mesmo uma energia potencial de repulsão de 7,3 J é suficiente para impedir a floculação, ao passo que no sistema com $\mathrm{pH}$ de 8,1 e razão polimérica de 1,2, o sistema permanece estável, apesar de a energia potencial de repulsão ser de apenas $0,5 \mathrm{~J}$.

Os dados denominados $\mathrm{C}$ confirmam a hipótese de que o total recobrimento das partículas é o principal fator a determinar se um sistema irá flocular ou não. Nestes dados a razão polimérica é sempre maior que 1 , e apesar da energia potencial de repulsão ser

Tabela I - Relação entre o pH de Suspensões de $\mathrm{Al}_{2} \mathrm{O}_{3}$ estabilizadas com PMAA e algumas propriedades da suspensão (2).

\begin{tabular}{cccccccc}
\hline $\mathrm{pH}$ & \multicolumn{2}{c}{$\begin{array}{c}\text { Razão } \\
\text { Polimérica }\end{array}$} & $\kappa_{a}$ & $\psi_{\zeta}(\mathrm{mV})$ & $\mathrm{cVr}(\mathrm{J})$ & $\begin{array}{c}\eta_{0} \text { a } \eta_{10} \\
(\mathrm{mPa} . \mathrm{s})\end{array}$ & Estabilidade \\
\hline 8,1 & $\mathrm{~B}$ & 0,76 & 139 & -35 & 1,4 & $220-405$ & $\mathrm{~F}$ \\
\hline & $\mathrm{B}$ & 0,95 & 152 & -41 & 1,0 & $60-205$ & $\mathrm{~F}$ \\
\hline & 1,2 & 164 & -37 & 0,5 & $37-37$ & $\mathrm{E}$ \\
\hline 8,1 & & 1,9 & 198 & -33 & 0,1 & $50-70$ & $\mathrm{E}$ \\
\hline & $\mathrm{C}$ & 0,95 & 265 & -26 & 0,0 & $415-645$ & $\mathrm{~F}$ \\
\hline & $\mathrm{C}$ & 1,2 & 271 & -27 & 0,0 & $55-82$ & $\mathrm{LF}$ \\
\hline 9,5 & $\mathrm{~B}$ & 0,55 & 279 & -22 & 0,0 & $50-60$ & $\mathrm{E}$ \\
\hline & & 1,2 & 135 & -31 & 7,3 & $55-115$ & $\mathrm{~F}$ \\
\hline 9,0 & & 1,7 & 163 & -32 & 0,4 & $205-215$ & $\mathrm{E}$ \\
\hline 8,8 & $\mathrm{~A}$ & 1,3 & 143 & -34 & 1,1 & $20-20$ & $\mathrm{E}$ \\
\hline 6,5 & $\mathrm{~A}, \mathrm{C}$ & 1,37 & 152 & -32 & 0,6 & $20-20$ & $\mathrm{E}$ \\
\hline 5,3 & $\mathrm{~A}$ & 1,2 & 213 & -24 & 0,0 & $45-50$ & $\mathrm{E}$ \\
\hline 4,6 & $\mathrm{~A}$ & 1,3 & 265 & -17 & 0,0 & $205-230$ & $\mathrm{LF}$ \\
\hline & & 325 & -13 & 0,0 & $1300-$ & $\mathrm{F}$ \\
\hline
\end{tabular}


zero, as suspensões permanecem estáveis, ou levemente floculadas.

\section{8 - Potencial Zeta de Partículas Estabilizadas} Eletroestericamente

Em partículas estabilizadas com polieletrólitos, seria de se esperar que as propriedades eletrostáticas da superfície fossem determinadas exclusivamente pelo polieletrólito, como foi sugerido na figura 7. A figura 8 mostra, entretanto, que as cargas existentes na superfície das partículas têm um efeito significativo na energia potencial eletrostática que se desenvolve ao redor das partículas.

Se não existisse interação entre o polieletrólito e as cargas superficiais das partículas, o potencial zeta seria uma função do número relativo de sítios $\mathrm{COO}^{-} \mathrm{Na}^{+}$dissociados (NRS), o qual é obtido multiplicando-se a quantidade de polímero adsorvido em determinado $\mathrm{pH}$ (figura 6) pela fração dissociada neste $\mathrm{pH}$ (figura 2).

Observa-se, entretando, que ao variar-se o $\mathrm{pH}$, o potencial zeta não acompanha o número relativo de sítios. Para $\mathrm{pHs}$ abaixo do ponto de carga zero (PCZ), há predomínio de sítios carregados positivamente na superfície das partículas, enquanto que em $\mathrm{pHs}$ acima do ponto de carga zero, predominam os sítios carregados negativamente. O potencial zeta é dado por uma somatória das cargas negativas desenvolvidas com a dissociação do polieletrólito e das cargas exis-

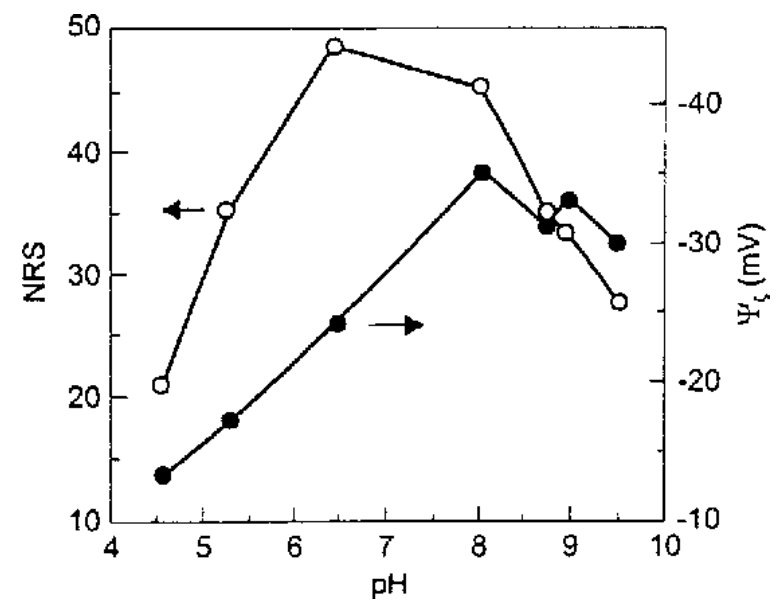

Figura 8 - Variação do número relativo de sítios (NRS) disponíveis para adsorção e do potencial zeta ( $\psi$ ) em função do $\mathrm{pH}$ da suspensão. (2)

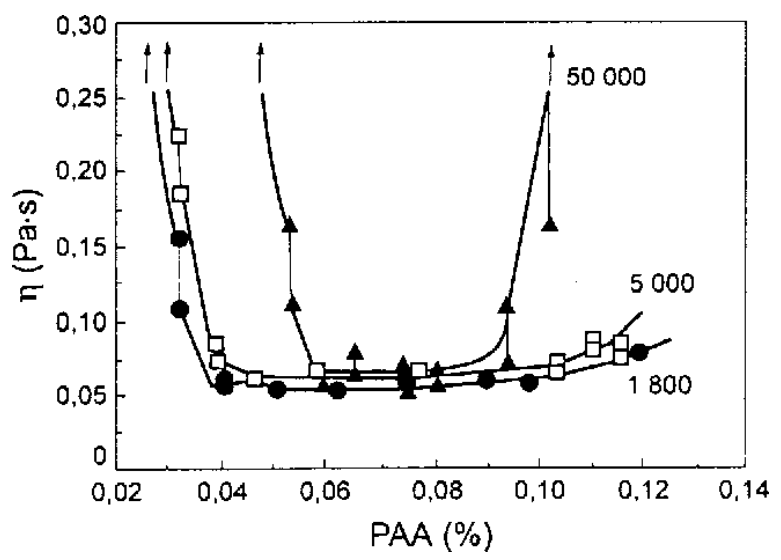

Figura 9 - Viscosidade ( $\eta$ ) de suspensões em função dos teores (\%) de poliacrilatos de sódio com diferentes pesos moleculares. (2) tentes na superfície das partículas. Portanto, abaixo do $\mathrm{PCZ}$ o predomínio de cargas positivas na superfície neutraliza parte das cargas do polieletrólito, resultando em potencial zeta menor do que o que seria verificado se não houvesse interação com a superfície. Já na região acima do $\mathrm{PCZ}$, há predomínio de cargas negativas, que se somam às cargas do polieletrólito, resultando em um potencial zeta maior do que o esperado. No pH 8,8 ocorre o PCZ, e a densidade de cargas superficiais é zero. Neste ponto, a contribuição das cargas superficiais sobre o potencial zeta é zero, e o mesmo é dado então apenas pela fração dissociada do polieletrólito.

\section{9 - Reologia em Função da Quantidade de Polieletrólito e} do Peso Molecular

A forma mais comum de se avaliar o efeito de um defloculante sobre uma suspensão cerâmica é através de uma curva de defloculação, que consiste em fazer-se medidas da viscosidade da suspensão em função do teor de defloculante adicionado. A figura 9 apresenta exemplos de curvas de defloculação de suspensões de alumina com teor de sólidos de $50 \%$ em volume, nas quais foram utilizados poliacrilatos de sódio com diferentes pesos moleculares como defloculantes.

A adição de pequenas quantidades do defloculante provoca uma queda acentuada na viscosidade das suspensões. Observa-se que à medida que se aumenta o peso molecular do defloculante diminui a sua eficiência, sendo necessária uma maior quantidade do mesmo para atingir um patamar de estabilidade. Isso é uma evidência de que talvez a espessura da camada adsorvida seja maior no caso de pesos moleculares mais elevados.

Após ter sido atingido o patamar da estabilidade, que significa o recobrimento total da superfície das partículas, qualquer excesso de polímero adicionado irá permanecer em solução. Sabe-se que a solubilização de um polímero em um líquido provoca aumento em sua viscosidade, sendo esse aumento tanto maior quanto maior o seu peso molecular. Isso é verificado no caso da amostra com peso molecular de 50.000, cujo excesso provocou drástico aumento na viscosidade da suspensão. Além disso, moléculas com alto peso molecular favorecem mecanismos de desestabilização como a floculação por depleção ${ }^{(8)}$, que consiste basicamente em um aumento na pressão osmótica entre as partículas devido à maior concentração de cadeias em suspensão, forçando-as a se aproximar. Favorecem também a ocorrência do "bridging effect", ${ }^{(9)}$ que consiste na ligação de uma molécula de polímero em duas ou mais partículas, provocando aumento na viscosidade do sistema. Esses dois efeitos ocorrem com menor intensidade no caso de moléculas com peso molecular menor, fazendo com que defloculantes com peso molecular menor sejam mais adequados ao processamento cerâmico ${ }^{(10)}$.

\section{CONCLUSÕES:}

O uso dos ácidos poliacrílico (PAA) e polimetacrílico (PMAA) como defloculante tem sido uma alternativa muito utilizada no processamento de cerâmicas refratárias e avançadas à base de alumina.

Quando em meio aquoso, essas moléculas sofrem dissociação, adquirindo cargas elétricas negativas. $\mathrm{O}$ grau de dissociação e a conformação molecular adquirida dependem fortemente do meio. Assim, a eficácia, bem como a quantidade de defloculante necessá- 
ria para promover a estabilização são fortemente dependentes do $\mathrm{pH}$.

Em sistemas à base de alumina, o uso de poliacrilatos e polimetacrilatos não se justifica em $\mathrm{pH}$ muito ácido, já que nessa faixa de $\mathrm{pH}$ a estabilização ocorre naturalmente, por meio eletrostático, sem a necessidade de se usar defloculante. A faixa de pH ideal para essa classe de defloculante é acima de 7,5. Nesta região, há um elevado grau de dissociação das cadeias, além de ocorrer adsorção de alta afinidade. Em $\mathrm{pH}$ básico, todavia, a adsorção torna-se gradativamente mais difícil, pois a densidade de carga superficial negativa das partículas de alumina aumenta com o $\mathrm{pH}$, constituindo uma barreira significativa em situações extremas.

Devido ao caráter eletrostático desta classe de defloculante, a força iônica do meio é também importante, influenciando o grau de dissociação das cadeias, e portanto, a eficiência do defloculante.

O total recobrimento da superfície das partículas é também fundamental para uma boa dispersão, tal como verificado na estabilização estérica.

O peso molecular das cadeias poliméricas é também de grande importância, sendo que polímeros com peso molecular médio elevado apresentam desempenho inferior.

\section{AGRADECIMENTOS}

Os autores agradecem à Fapesp e ao CNPq pelo apoio recebido na execução desse trabalho.

\section{BIBLIOGRAFIA}

[1] PRADIP, R.S., PREMACHANDRAN and MALGHAN, S.G. "Electrokinetic Behaviour and Dispersion Characteristic of Ceramic
Powders with Cationic and Anionic Polyelectrolytes", Bull. Mater. Sci., 17 [6] 911-920,1994.

[2] CESARANO III, J.; AKSAY, I., A. - "Processing of Highly Concentrated Aqueous - Alumina Suspensions Stabilized with Polyelectrolytes"; J. Am. Ceram. Soc., 71 [12] 1062-1067, 1988. [3] HIRATA, Y.; KAMIKAKIMOTO, J.; NISHIMOTO, A.; ISHIHARA, Y. - "Interaction between $\alpha$-Alumina Surface and Polyacrylic Acid"; J. Ceram. Soc. of Japan, 100 [1] 7-12 (1992). [4] CESARANO III, J.; AKSAY, I.; A.; BLEIER, A. - "Stability of Aqueous Alumina Suspensions with Poly (methacrylic acid) Polyelectrolyte"; J. Am. Ceram. Soc.; 71 [4] 250-255, 1988.

[5] SACKS, M.D. - "Principles of Dispersion of Powders in Liquids"; apostila do curso oferecido ao PPG-CEM da UFSCar em novembro de 1995.

[6] CHOU, K.; LEE, L. - "Effect of Dispersants on the Rheological Properties and Slip Casting of Alumina Slurry"; J. Am. Ceram. Soc., 72 [9] 1622-1627, 1989.

[7] HIMENZ, P.C. - "Principles of Colloid and Surface Chemistry"; Second Edition Revised and Expanded, editado por Marcel Dekker, Inc. 1986.

[8] HORN, R.G. - "Surface Forces and Their Action in Ceramic Materials"; J. Am. Ceram. Soc., 73 [5] 1117-1135, 1990.

[9] LEONG, Y.K.; SCALES, P.J.; HEALY, T.W.; BOGER, D.V. "Interparticle Forces Arising from Adsorbed Polyelectrolytes in Colloidal Suspensions", Colloids and Surfaces A: Physicochemical and Engineering Aspects, 95 (43-52), 1995.

[10] OKAMOTO, H.; HASHIBA, M. Y., HIRAMATSU, K "Fluidity and Dispersion of Alumina Suspensions at the limit of Thickening by Ammonium Polyacrylates", J. Mater. Sci., 26 (383387), 1991.

(Rec. 3/97, Ac. 3/97) 